\title{
Exploring Young Offenders' Conceptions of Meaningful Employment
}

\author{
Rebecca Jayne Oswald ${ }^{1}$
}

Accepted: 29 November 2021 / Published online: 14 December 2021

(c) The Author(s) 2021

\begin{abstract}
Experiencing meaningfulness at work is important for employee engagement, individual performance, and personal fulfilment. However, research surrounding meaningful employment has predominantly focused upon the experiences of welleducated, adult professionals. To expand theoretical understanding of this concept, this paper investigates perceptions of meaningful employment among youths from Northern England (aged 16-18) with a history of involvement in crime. Interviews demonstrate that young offenders' criteria for 'meaningful work' differ from existing research and is influenced by their self-concept and inherent values as youths from chaotic and impoverished backgrounds. This highlights the subjectivity of this concept. Nonetheless, the findings also indicate that there are instances where work itself makes a broader contribution in discovering meaning, and therefore, certain organisational practices are experienced as meaningful by both young offenders and adult professionals. Thus, this study demonstrates the importance of surveying diverse populations to reach a more comprehensive understanding of meaningful employment.
\end{abstract}

Keywords Meaningful employment · Youth · Young offender · UK

\section{Introduction}

King et al., (2016: 212) define meaningfulness as the feeling that our life has 'purpose, significance, and coherence'. They explain that purpose refers to having goals and direction for our lives. Significance entails the degree to which a person believes his or her life has value, worth and importance. Coherence allows life to make sense to the person living it. Thus, finding meaning is an integral part of human existence; it can help answer the broader existential question: 'why am I here?' (Pratt \&

Rebecca Jayne Oswald

rebecca.j.oswald@northumbria.ac.uk

1 Department of Social Sciences, Northumbria University, Lipman Building,

Newcastle-upon-Tyne NE1 8ST, UK 
Ashforth, 2003). Scholarship across a range of disciplines-such as sociology, psychology and philosophy_details the value of 'meaningful work'. Engaging in meaningful employment is important for individual employees, as experiencing meaning is essential for healthy psychological functioning and human flourishing (Frankl, 1992; Routledge et al., 2011; Ryff \& Singer, 1998). Meaningful employment is also important for employers, due to its positive effects upon employee engagement and productivity (Christian et al., 2011; Humphrey et al., 2007; Nikolova \& Cnossen, 2020). There are several organisational practices typically associated with experiences of meaningfulness. Employees describe employment which has transcendent benefits, has opportunities for personal achievement and learning, provides interesting work tasks, allows for self-determined working and promotes social bonds amongst co-workers, as meaningful. However, meaningful employment literature predominantly focuses upon the experiences of well-educated professionals. Children and adolescents' understandings of meaningful employment have also rarely been explored.

Therefore, this article extends the research surrounding meaningful employment by investigating conceptions of meaningful work with a very different population to those previously surveyed: young people from Northern England (aged 16-18) with a history of involvement in crime. The subsequent section provides the background for this paper, outlining the present meaningful employment scholarship in the form of a typology of organisational practices that employees report creating meaning in their work. Following a consideration of the over-representation of well-educated professionals in this scholarship, the paper turns to young offenders' perceptions of meaningful employment. It describes the methodology used in this study and presents an updated typology of meaningful employment for young offenders. Finally, it discusses the implications of this typology for present understandings of meaningful employment.

\section{Theoretical Background}

\section{A Typology of Meaningful Work}

Meaningful employment scholarship details an array of employment practices which employees have stated make work meaningful. In this section, a typology of these organisational practices is presented. Whilst acknowledging that some may overlap, and they may not encompass all the research into meaningful employment, the aim is to categorise the main findings of the literature in this area.

\section{Provides Work with 'Transcendent Benefits'}

Singer (1995) argues that to find meaning, the cause for which individuals work must be a transcendent one: it extends beyond the boundaries of self and 'makes the world a better place to live in'. Indeed, Bailey and Madden (2015) found that academics, refuse collectors and stonemasons - although from very different professions - all described their work as meaningful because of its positive contribution 
towards a greater good and its value for future generations. A number of scholars report that an individual can find meaning from even the most mundane work task if they can connect it to a larger, more significant, cause (Allan, Duffy \& Collison, 2018; Lips-Wiersma \& Morris, 2009), in particular if they have contact with the beneficiaries of their work (Grant et al., 2007; Grant, 2008; Grant \& Hoffman, $2011 \mathrm{a}$; b). Therefore, work with transcendent benefits elucidates feelings of meaningfulness because it allows the individual to feel that they serve a wider purpose in society. Connecting to something greater than one's self is a key way to create a sense of significance in one's life and a greater understanding of why we are here. The literature also mentions that working for a company whose occupational mission is for the greater good may invoke feelings of meaningfulness among workers due to the positive public perceptions of the work they do (Rosso et al., 2010). Perceiving that others around you believe you are making valuable societal contributions enhances feelings of meaningfulness.

\section{Provides Opportunities for 'Learning/Skill Development'}

Opportunities for learning and skill development in employment can evoke feelings of meaningfulness. Several studies have found that work is meaningful if it results in personal growth through ongoing learning; there is inherent meaning in successfully mastering new skills (Allan et al., 2016; Bowie, 1998; Lips-Wiersma \& Morris, 2009; Steger et al., 2012). Developing our abilities boosts self-esteem and promotes feelings of worthiness, which naturally enhances the feeling that our life - and ourselves in it-has significance and meaning (Rosso et al., 2010). Moreover, if the acquisition of knowledge is something that an individual specifically values, then undertaking work that can fulfil this will necessarily invoke feelings of meaningfulness (Park \& Choi, 2016). This is because meaningful employment involves not only work that 'makes meaning' itself, but also work that aligns with already held values (Steger et al., 2012). It means that our work role fits our ideals for what is important in life, which gives that life a greater sense of coherence.

\section{Provides Opportunities for 'Personal Achievement'}

Opportunities for personal achievement at work can also be meaningful. Although related, this is to be distinguished with the two preceding sections. 'Personal achievement' at work does not necessarily involve 'doing good' for others; rather, it is an individual sense of achievement. Moreover, personal achievements do not have to involve learning new skills. Rather, such an organisational practice is largely concerned with job performance and task accomplishment. For example, a common articulation from employees is that a sense of meaningfulness arises when standing back to admire the completion of a piece of work (Bailey \& Madden, 2015; Pratt $\&$ Ashforth, 2003). Such positive feelings of achievement at work, as with learning new skills in the previous section, enhances one's sense of worthiness and self-efficacy which can make one's life feel more meaningful (Rosso et al., 2010). Indeed, as Ryan and Deci (2000) purport, perceiving a sense of 'competence' - that one can effectively perform tasks of varying complexity-is a basic psychological need. An 
important source of competence need fulfilment can be feedback and encouragement provided by others who view one's accomplishments positively (Ryan \& Deci, 2017). Thus, personal achievement at work can affect not only how we feel about ourselves, but also how others view us. As May et al. (2004) explain, experiences of meaning can be attained through feeling that others view our work performance positively.

\section{Provides'Interesting'Work Tasks}

Rosso et al. (2010), in their review of meaningful employment research, found that employees who characterised their work as meaningful related this to perceptions of enjoyment or interest in work. Indeed, research consistently demonstrates that individuals find employment that involves both task and skill variety meaningful (Fried \& Ferris, 1987; Pratt \& Ashforth, 2003; Steger et al., 2012; Veltman, 2015; Allan, Duffy \& Collison, 2018). Interesting work may invoke feelings of meaningfulness because 'interest' is a positive emotion following cognitive appraisal (Silvia, 2006). Research demonstrates that experiences of positive emotions and mood can be meaningful (Hicks \& King, 2008; Hicks, Schengel \& King, 2010; Ward \& King, 2016).

\section{Allows for 'Self-Determination' When Working}

It has been widely reported that employees find jobs that allow for the use of 'selfdetermination' skills_-such as self-management, decision-making, problem-solving, initiative and independence-more meaningful (Bowie, 1998; Carter \& Lunsford, 2005; Bailey \& Madden, 2015; Allan, Duffy, \& Collisson, 2018; Nikolova \& Cnossen, 2020). Supporting this, Lips-Wiersma and Morris (2009) found that meaningless work is typically associated with working conditions where there is excessive control over the actions of employees. Deci et al. (1989) explain that self-determined employees can experience feelings of meaningfulness because they have the autonomy to construct their work in a way that it provides meaning for them. Moreover, 'self-determination' theory in psychology purports that human beings are naturally predisposed to seek autonomy in their lives (Ryan \& Deci, 2000). Thus, most individuals will experience work that satisfies this desire for self-determination as meaningful because this is a significant value in their lives, which they seek to fulfil (Steger et al., 2012).

\section{Promotes 'Social Bonds'}

Research demonstrates that employees who have rewarding interpersonal interactions and share values with their co-workers perceive their employment to be more meaningful (Ashforth \& Kreiner, 1999; Bechky, 2003; Grant et al., 2008; May et al., 2004; Nikolova \& Cnossen, 2020). Organisations that create close-knit, family-like dynamics among members of the workforce can promote this, as can those that encourage team-working (Pratt \& Ashforth, 2003). In social psychology, scholars explain that a fundamental human need is to experience 'relatedness': the 
development of secure and satisfying connections with others in one's social surroundings (Ryan \& Deci, 2000). As explained earlier, employment is meaningful if it aligns with the individual's overarching values (Steger et al., 2012). Therefore, employment that fulfils this desire for relatedness, and allows the individual to feel connected to others, will be meaningful for most.

\section{Participants in Meaningful Employment Studies}

Overall, present scholarship suggests that employment featuring the organisational practices specified above will generate experiences of meaningfulness for employees. However, this may not apply to the participants in this study. The meaningful employment literature has been dubbed as 'painfully elitist' (Rosso et al., 2010) because it predominantly focuses upon the experiences of middle-class professionals. Indeed, several studies admit that white and highly educated persons are overrepresented in their samples (Allan et al., 2016; Lips-Wiersma \& Morris, 2009; Steger et al., 2012; Hirschi, 2012). Even where lower-status and less-skilled occupations are examined, for example, Bailey and Madden's (2015) study which included refuse collectors, these have not included employees under the age of 18 or those with a history of persistent offending. The young people in this study are at a considerable distance from the labour market, due to their lack of qualifications, limited employment history and criminal record. As a result, they may have quite different ideas about what constitutes meaningful work. Therefore, this paper explores whether participants find the typology of organisational practices specified above to constitute meaningful employment, and why: what is the source of meaning and is this the same as for adults? It also considers whether there are other organisational practices they consider meaningful. The aim is to test the applicability of existing scholarship to more diverse populations, as well as enhance understanding of what it is to have 'meaningful' employment through in-depth discussions with participants.

\section{Methods}

This article is based on data collected (during 2017-2019) for a $\mathrm{PhD}$ project involving young people $(n=23)$ employed by the Green Light ${ }^{1}$ (GL) social enterprise. The GL provides those who have been involved with the youth justice system 6 months paid employment, as an opportunity to turn their lives around. Any youths who are or have recently been under the supervision of their local Youth Justice Service, are between the ages of 16 and 18 and are not considered to be high risk of harm, are eligible to be involved in the scheme, though participation is voluntary. At the GL, young people work in small cohort groups - a maximum of five employees and the supervisor-which aids risk management and mentoring. All the work that the GL youths undertake is outdoors, such as painting, fencing, gardening, dry stone

\footnotetext{
1 The Green Light (GL) is a pseudonym, as are all names presented in this paper.
} 
walling, flood mitigation, and building habitats. Consequently, the GL provided an excellent opportunity to explore meaningful employment with this population, as it exposes youths to a variety of work tasks that they may not have experienced otherwise due to their lack of qualifications, minimal employment histories and criminal records.

Access to participants was gained through the social enterprise, who acted as a gatekeeper. The GL currently operates in ten locations in the UK. No selection process was made for participants; they were the entire cohort groups for the three GL sites (all Northern England) surveyed for the period of this research. Twenty-two of the young people were male and one was female. One young person was black, two young people were of mixed race and all the others were white. All the employees were between the ages of 16 and 18 when commencing work with the GL. Referring to official records, all the employees had committed multiple offences prior to engaging in the GL, the average was 12 . The most frequently committed offences included criminal damage, burglary, common assault and shoplifting, which the Youth Justice Board grades as mid-serious offences.

Whilst the number of participants in this study may appear small, and raise potential concerns around the generalisability/utility of the findings, the number of youths entering the youth justice system in England and Wales is decreasing (Ministry of Justice, 2021). Indeed, the participants of this study still represented approximately $7 \%$ of all medium risk, 16-18-year-old service users of the three localities surveyed during the period of this research. Furthermore, having a relatively small number of participants was beneficial in this study. It allowed for repeated contact and relationships to be built with each of the youths. Understanding concepts such as 'meaning' requires more than a surface-level investigation into the social realties and life-worlds of participants. It took time to develop a deep and contextualised understanding of meaningful employment with each individual.

Those who remain in the youth justice system in England and Wales are often the most difficult to rehabilitate and arise from the most dysfunctional and chaotic backgrounds (Taylor, 2016). Indeed, this is reflected in some of the characteristics of the young participants in this study. Twenty percent of participants were or had been looked after children, compared to only $0.67 \%$ of under- $18 \mathrm{~s}$ in England (Department for Education, 2021a). Seventy-three percent of young people had been excluded from school, compared to only $0.1 \%$ of all children enrolled in schools in England (Department for Education, 2021b). Where known, 92\% of young participants lived with other offenders.

Interviews were the primary source of data for this article. Face-to-face interviews were conducted with young people on their first week at the GL, 3 months in and on their last week of employment. Interviews were recorded and transcribed; on average, first-week interviews lasted $10 \mathrm{~min}$, and 3-month and 6-month interviews lasted $30 \mathrm{~min}$. During interviews it was discussed with youths, in a broadly unstructured manner, which organisational practices they deemed to be valuable. The first-week interviews related these discussions to past involvement in employment (if any) and current experiences of working at the GL. The 3-month and 6-month interviews continued these broad discussions but also focused on what sort of work youths would like in the future and what would be important from this employment. 
Also utilised in the 6-month interview was a framework containing the six organisational practices existing scholarship associates with experiences of meaningfulness (see above). It was requested that participants number each organisational practice from 1 to 5, depending on how important the presence of each would be in a future job, with 1 representing not important and 5 as very important. ${ }^{2}$ This provided a straightforward and visual representation of which organisational practices from the existing typology participants—on face value-considered important in future employment. Consequently, in the final interviews, discussions could explore further the organisational practices youths had mentioned in the open conversations and those they had rated highly (or not so highly) in the framework-why were they important or unimportant? It was interpreted from their answers whether young people were describing that such work gave a sense of meaning to their lives.

Investigating meaningful employment in this manner was intended to maintain a balance between keeping the conversation open and unguided and exploring the necessary concepts. It allowed the relevance of the existing typology of meaningful organisational practices to be considered, whilst being sensitive to other organisational practices young offenders may find gives their work meaning. Naturally, it would have been unfeasible to ask young participants-with limited educationwhich organisational practices gave wider purpose, significance or coherence to their lives (King et al., 2016 definition of meaningfulness). Indeed, the challenge of investigating meaningful employment with this population should be acknowledged. Sometimes young people lacked the confidence, motivation or communication skills to discuss their experiences of employment in detail. Swain (2016) estimates that over $50 \%$ of male young offenders have a clinically significant learning disorder, which can affect narrative skills.

Interviews with GL supervisors $(n=4)$ and participant observations at GL worksites (over $200 \mathrm{~h}$ ) were also used to investigate meaningful work. For example, inquiries were made with supervisors as to how young people engaged with different types of work and which they responded most positively to. This was also confirmed through participant observations. However, the data gained from supervisor interviews and participant observations was used primarily to supplement the youths' interview data. The aim of this study was to investigate young offenders' understandings of meaningful employment, and their voices and perspectives were therefore prioritised. During observations, I worked alongside youths as another employee. Detailed notes were written at the end of each day of fieldwork. Including participant observations in the research design was important because of the differences in positionality between myself and the participants. Most participants were young males, who often had experienced poverty, childhood traumas, domestic violence, and unstable living conditions. As a female and a student, I lacked 'cultural credibility', potentially meaning that participants would be less likely to confide in me (Caelli et al., 2003). Nonetheless, spending time immersed in their working environments expanded my understanding of the participants' worldview and vice versa.

\footnotetext{
2 This data was used as a tool to prompt further discussions in interviews; it did not form part of the findings for this paper.
} 
It led to the sharing of experiences and rapport being built, which allowed for the collection of richer and thicker data during interviews than would have otherwise been possible. It also helped address the potential power imbalance between myself and the participants (Gallagher, 2008).

Interview transcripts and field notes were thematically analysed, following Thomas's (2006) general inductive approach. A thorough coding process was developed-involving familiarisation with data, generating initial codes and searching and reviewing key themes (Braun \& Clarke, 2006). Data coding was conducted in three phases. The first phase involved coding based on empirical (inductive) categories that emerged through the exploration of data. This made it possible to be receptive to the employment practices that these young people in particular found meaningful. Secondly, all data was read again and coded based on sensitising or 'a priori' (Gibson \& Brown, 2009) categories: those based on the typology established in the literature review, such as 'achievement', 'interest' and 'skill development'. Thirdly, sensitising and emerging categories were reviewed and consolidated as a basis for the creation of an updated typology of meaningful employment for young offenders. Data analysis was undertaken by a single researcher in this study. This was partly because it formed part of a $\mathrm{PhD}$ project. However, analysis by another researcher was also less appropriate. As I had spent a considerable period immersed in young people's working environments, interpretations of the data were informed by my unwritten 'human' impressions and relationships with these young people. The inclusion of successive interviews within the research design ensured the validity and trustworthiness of the thematic analysis (Nowell et al., 2017). Data collection and analysis took place simultaneously in this study. As a result, in subsequent interviews, the researcher could return to participants to clarify and validate tentative findings.

Approval was gained for this project from the University Ethics Committee. The participants in this study were mostly aged under-18 and had long been disengaged from formal education. Conducting observations and interviews with these individuals could have presented an ethical issue. Such participants were more vulnerable as they may have less ability to understand the nature of the research and any potential risks in participating (Caulfield \& Hill, 2014). This was addressed by the creation of user-friendly information sheets at the appropriate level for participants. Time was also spent explaining the nature of the research to young people, and for those under the age of 18 , consent of a parent/guardian was sought.

\section{Findings}

In presenting the findings, this paper firstly outlines the extent to which the typology of meaningful organisational practices above (research primarily conducted with adult professionals) met young people's criteria for meaningful work. Secondly, it details the other organisational practices young people described as engendering meaning in their work that were not specified by adult professionals. Finally, it compares the organisational practices that make work meaningful for adult professionals and young offenders. 


\section{Organisational Practices from Existing Typology}

\section{Provides Work with 'Transcendent Benefits'}

GL youths found meaning in work that they knew would have a beneficiary. By contrast, they found it very demoralising to do work that they deemed to have no wider consequence upon the world. For example, Darrell described:

The work we were doing today was important because the wall will look nice for when people walk past with their dogs. The tree-planting jobs they are really important and good for obviously the environment itself. But there's a mix - some is pointless. We were putting flowers in a flowerbed outside a cabin on a building site, but it's just where people go to put their timesheets in. There's no point to work like that, like there's literally no point to us at all

Thus, Darrell only perceived that work that had benefits for the greater good gave him a sense of purpose or 'point' to him as a worker. It was important to young people that their good work 'lasts'. For example, I witnessed young people's despondence when they cleaned up a playground only to later find it had been vandalised again. Moreover, I observed their frustration if the vegetation they had spent hours cutting back to help prevent flooding was left to grow back in by the council. Even though young people were paid regardless, many felt dissatisfaction with their work if they believed it served no wider purpose. Consequently, this suggests that work with transcendent benefits was meaningful to young people for the same reason as adult employees (see Lips-Wiersma \& Morris, 2009; Bailey \& Madden, 2015; Allan, Duffy \& Collision, 2018); it gave them a sense that they had an impact upon the world and therefore a meaningful purpose.

As with adult professionals, some young people found meaning in work that 'does good' because it engendered the positive reactions of others (see Rosso et al., 2010). Julie described:

You are actually doing something that people realise. Like when we were literally like just taking like plastic tree guards off the trees... like five passerby's were like aww you's are doing a fantastic job and the neighbourhood actually realises what you are doing and they appreciate it.

Similarly, John explained:

It's making it a better place isn't it? When we done the fencing all the fences were like broken down and that and by the end it was spotless ... Everyone was telling weh we were doing a good job. It was worth our time doing that job...with all the thanks and that we were getting and that it felt good to actually be doing something

The positive feedback from community members greatly contributed to the participants' sense that the work they were doing was making a real difference to the community and had a greater purpose. 


\section{Provides Opportunities for 'Learning/Skill Development'}

GL youths had long been disengaged from formal education. Most had been excluded from school after many years of truancy and suspensions for problematic behaviour. Yet, despite this, many described employment that provided opportunities for learning as meaningful. Several participants expressed regrets that they had not attended school when they were younger and gained qualifications. They believed learning at work could lead to a better future. For example, Max expressed that if he could gain qualifications or learn a new skill, he could 'go anywhere'. It was found by Park and Choi (2016) that employee learning can be meaningful if the employee already recognises learning as valuable.

Indeed, most young people preferred the more skilled and challenging work that they engaged in at the GL. In addition to fulfilling their desire to learn, this may be attributed to the fact that young people felt that more skilled work was what 'adult workers' did. Jay illustrated this:

Interviewer: 'What type of work do you like best?'

Jay: 'God anything but litter-picking that's just shit, does my head in like a said ... the fencing, I enjoyed the fencing, its proper work you nah - me mates' Dad puts fences up'

Interviewer: 'What did you enjoy about fencing?'

Jay: 'Well, you've got to do the heighting and the measuring. Bit more of a challenge, it's just work, its proper work. Like with the fencing, I've got a job to do and I'll do it, get me head down and get it done.'

Jay repeatedly references fencing as 'proper work' and a 'job', which demonstrates how he believed this skilled activity was representative of adult employment. By contrast, litter picking was not considered proper employment by young people-despite the fact that many adults are employed in this occupation. As Glenn explained:

It's like we are doing community service. Cos obviously when we're doing the litter picking with our coats and that on...

Participants desired the higher social status of 'adult worker' rather than 'young offender'. Skilled work that achieved this desire could therefore invoke feelings of meaningfulness; work that young people connected with juvenile reparations could not. Why was it important to young people to do work with 'adult' status? Moffit (1993) explains that during adolescence, young people feel likeand biologically have become - an adult but are largely treated by society as a child. Proving maturity and autonomy are very important at this time. Massoglia and Uggen (2010) report that delinquent youths are even less likely to be viewed as mature by adults because of their behaviours. Thus, as proving 'adult status' was particularly important to the youths in this study, employment that aids this will be meaningful as it reverberates with their ultimate concerns (Steger et al., 2012). 


\section{Provides Opportunities for 'Personal Achievement'}

As Bailey and Madden (2015) report with adult employees, many GL youths found meaning in being able to step back and survey what they had achieved in the working day. Supervisor Greg described, 'for a lot of our young people they've got to see the completed product at the end of the day, because if they don't they think it's meaningless'. The more 'visual' the achievement, the more likely young people were to feel that their work was meaningful. For example, young people were observed admiring the bench they had built and counting how many bags of leaves they had collected that day. As this excerpt from Scott's interview demonstrates:

Interviewer: 'What sort of job would you like in the future?'

Scott: 'Something hands on and manual, something like a builder, something where you can step back and you can look at like... the thing is with an electrician... all the work is hidden, like behind walls and that, I like being able to look back and think - I built that... Like it's an achievement makes us feel worthwhile actually getting shit done'

Young offenders-like adult professionals-found that achievement at work gave them a sense of self-efficacy and worthiness. Such feelings can evoke experiences of meaningfulness (Rosso et al., 2010).

Supervisors routinely gave young people praise, even for the completion of small tasks, as illustrated in one supervisor's comments:

I try to give the lads a lot of praise, most of them thrive off of praise. Some of them have never been praised... more often than not they are told they're a waste of space

Accordingly, whilst young people were similar to the adult professionals surveyed in the meaningful employment literature, in the sense that they also valued work that gave opportunities for personal achievement, this was especially meaningful to this group. The participants of this research are a group of individuals who are used to receiving mainly negative feedback from others regarding themselves and their abilities - such as family members, schoolteachers, criminal justice workers, and social workers. Engaging in work that allowed others to see that young person's capabilities was therefore meaningful to young people.

\section{Provides 'Interesting' Work Tasks}

In contrast to the research conducted with adult professionals (Fried \& Ferris, 1987; Pratt \& Ashforth, 2003; Steger et al., 2012; Veltman, 2015; Allan, Duffy \& Collison, 2018), 'interesting work' did not appear to be amongst participants' criteria for meaningful employment. As Dale described, when asked if having an interesting job was something he desired in the future: 'I don't think it's really important is it? Work is... just needs to be done. Get your pay, that's it'. Likewise, 
Alexander stated: 'yeah, great if you can get something interesting, but it's not important, you can still do the work and you can't live off nowt'.

When exploring the reasons for this, it was found that some young people had no expectations for their future work to be interesting and therefore could not anticipate this as a source of meaning. For example, a supervisor explained:

Getting an interesting job is a bonus. I've asked young people, if I had a magic wand, what job would they want to do? And they say something and I say to get that, you'd have to go back to school, do your English and your

Maths. And then you might have to go to University. It's all these obstacles in front of what they want.

This supports the findings of Johnson (2002) who reports that young people from disadvantaged backgrounds will reassess the desirability of job rewards, such as inspiring interest, that are less accessible.

\section{Allows for 'Self-Determination' When Working}

The value of autonomous working divided young people's opinions. As with interesting work, some participants thought it unlikely that they would attain work where they were not under the control of others and deliberately reassessed the desirability of such organisational practices. As Dean stated: 'Don't you only get that when you're higher up? Not that bothered to be honest'. Furthermore, Alexander affirmed: 'I'd say that's not very important. I'm ok with being told to do this and do that'. On the other hand, some youths expressed that it would be important to them in future employment to be able to take initiative in their work. Indeed, several young people described that it would be their 'dream' to be selfemployed, so that they could be their own boss and set their own hours.

Young people considered self-determined work to be work of adult status. Indeed, employees expressed that working at the GL felt more like 'real work' to them when the supervisor let them choose how to complete work tasks. The desire to be treated as an adult worker was evident in the conversation with Julie about the supervisor:

Julie: 'He treats us like an adult. He lets us get on with our work like how we want to do it, he's not on us all the time, I couldn't stand that. It's not like the rest of the YOT you know, they're always like do this don't do that. Greg's different...'

Interviewer: 'And do you prefer to be treated as an adult?'

Julie: 'Definitely. Definitely. Cos obviously like we are... like I've got me own tenancy and stuff.'.

Julie described how having autonomy at work resonated with her need to be considered an adult. Therefore, whilst psychologists Ryan and Deci (2000) purport that all human beings are naturally predisposed to seek autonomy in their lives, for adolescent offenders - who desire 'adult status' at a time when they are 
largely treated as a child by society (Moffit, 1993) - this was particularly significant. Therefore, employment that allowed for self-determination when working was meaningful to these participants.

\section{Promotes 'Social Bonds'}

Many young people described 'working with people they liked' as very important. They explained that it was imperative to be able to have 'banter' with their workmates. As Glenn detailed:

Like you can't go to work and you can't be like all professional 24/7. Like obviously you've got to be able to have a bit of banter. Got to be able to have a laugh and shit like that.

The particular organisation of the GL enterprise-with small work teams of similarly situated young people-meant that most participants became friends rather than merely work associates. For example, Scott described:

The best thing about the [GL] in my opinion is that it is a small group so you get to know the people you are working with if you know what I mean? You get to know them for who they are rather than just like... working with a lot of people but not even knowing their names. I worked with Dean, Ross and Alexander like for... I'd say we are quite close now, we're quite close.

Several other young people stated that the best thing about the GL was 'the banter with the other lads' or the 'positive energy of the group'. As numerous researchers have discovered with adult professionals (Ashforth \& Kreiner, 1999; Bechky, 2003; Grant et al., 2008; May et al., 2004), young offenders found meaning in their bonds with their co-workers. Some employees formed particularly close relationships, as described by Joseph:

William he is like really easy to get on with and understanding and shit... you can just speak to him about 'owt. Like you can just go to him and you can say anything because he is not the kind of person that would cut you off, he'll sit there and he'll talk

In most cohorts, the 'close-knit' social dynamics depicted by Pratt and Ashforth (2003) as important for deriving meaning from work were observed. Such a working environment allowed young people to experience 'relatedness', which Ryan and Deci (2000) describe as a fundamental human need.

\section{Organisational Practices Not Specified in Existing Typology}

There were organisational practices not specified in the existing literature on meaningful employment that young people described giving their work meaning. This section considers these. 


\section{Provides an 'Adequate Income'}

Hitherto, this paper has considered sources of meaningfulness that are 'intrinsic' to the work role. Existing meaningful employment scholarship is largely hesitant about the role of extrinsic sources of meaningfulness in work. The consensus appears to be that adequate pay and job stability are not sources of meaning in themselves; however, their absence can restrict the ability of employees to find meaning in their work. Only those who have stable work and their needs met through the attainment of an adequate income can afford the luxury of seeking further self-fulfilment in work (Ayers et al., 2008; Baumeister, 1991; Bowie, 1998; Bunderson \& Thompson, 2009; Nikolova \& Cnossen, 2020; Veltman, 2015; Wrzesniewski, 2003). This consensus does not apply to the participants of this study. Young people found inherent meaning in the income they received from working because it gave them 'provider' status, as Julie ${ }^{3}$ described:

'Like it's the fact of like ... you're working for your own money and it's like all my family's been on the dole and its ladgeful ${ }^{4} \ldots$ Like before I had started and stuff I was just like waiting for the money off my social worker I felt like a proper tramp. Now I can hold me head up because I'm providing for me-self'

Thus, it was not simply acquiring money that was meaningful to young people; it was important that they 'earned' their pay. As Alexander expressed:

I don't think it's fair that some people have to work for their money and some people get it handed out. I'd get off my arse and earn it me, not just take what's given.

Confirming Jensen and Tyler's (2015) assertions regarding the emergence of an anti-welfare common-sense, participants had an inherent contempt of those who were dependent upon state benefits. Young people found earning their money through their own efforts gave them a sense of pride and was meaningful to them. Furthermore, considering young people's regular exposure to poverty and the harms it causes, it was unsurprising that one of their 'ultimate concerns' was to achieve a degree of financial security. Employment that aligns with this goal would therefore be meaningful to young people (Steger et al., 2012).

\section{Provides 'Stable' Work}

Job stability was what participants desired above all else in future employment. Indeed, many young people expressed that they would be happy to do any form of employment in the future, if only they could obtain something that would 'last'. As Max described:

\footnotetext{
${ }^{3}$ However, the sample of females was so small $(n=1)$ that it is unclear whether being a provider was equally meaningful to both young male and female offenders. Future research could explore this further.

${ }^{4}$ Slang for embarrassing/shameful.
} 
All I want is a job really. One that's full-time. I couldn't deal with having like a zero hours contract and getting up in the morning not knowing that $\mathrm{I}$ have a job to go to. I want something that's reliable

One of the reasons steady employment was so important to participants was because of their need to occupy their time. Prior to commencing the GL scheme, many participants described 'lying in bed all day', 'sitting around the house doing nowt' and 'hanging on the streets with my mates, bored'. MacDonald and Shildrick (2007) similarly found that materially deprived young people had such limited leisure lives that one of their main concerns was 'filling time'. Young people were desperate to avoid this feeling of emptiness and meaninglessness. Furthermore, keeping occupied through working was important to young people as a means of distracting themselves from dwelling on past/present traumas. As Julie described:

when I wasn't working I was just like going radge ${ }^{5}$ and stuff and I just need to keep occupied and stuff cos of the bairn and that's got leukaemia and I was only like getting one contact a week .... and it was just like doing my head in

In the existing research on meaningful employment, adult professionals did not refer to the ability of work to occupy their time and mind as a source of meaning. This is understandable because - as we can see above - the reasons young people give for needing to keep busy are very particular to their social position as youths from chaotic and impoverished backgrounds. Stability was something that the youths continuously sought in their turbulent existence. Youths described needing a single purpose they could work towards; secure employment would give a sense of coherence in their lives (part of King et al.'s (2016) definition of meaningfulness).

\section{Provides ‘Manual'Work}

Many participants expressed that they preferred practical, 'hands-on' work. This was not mentioned in research with adult professionals. Young males in particular found the physically demanding work at the GL meaningful. Several employees took pride in explaining that they were a 'good grafter' and would emphasise the occasions they had done 'back-breaking' work. As a supervisor stated:

It's the more manual work which generally suits all of our young people. Yeah, it's the heavy, digging mud, rather than the gardening. I mean they engage with the gardening, they enjoy it, but I think they enjoy more getting their hands dirty.

Young men found meaning in this work because it resonated with traditional hegemonic working-class ideals of masculinity, such as 'toughness' and 'strength' and 'machismo' (Connell, 1995; Ghaill, 1996; McDowell, 2003; Slutskaya et al., 2016). The young employees esteemed these values, due to the environments in which they resided. Supervisors explained that growing up on the estates that these young people

\footnotetext{
${ }^{5}$ Slang for 'crazy'.
} 
had meant they 'had to be tough or they were finished'. Therefore, when young people felt their work allowed them to achieve this, it had inherent meaning. Some young men also believed that 'hard graft' was what adult males did and therefore again this made work meaningful for them as it fulfilled their aspirations to attain 'adult' status.

\section{Provides ‘Outdoor'Work}

A final unexpected theme that appeared in young people's discourses regarding meaningful employment was the importance they placed upon the setting of their work. Young people found meaning in working outdoors, particularly in rural settings. A few participants described previous employment where they were indoors all day as frustrating and stressful. For example, Glenn disclosed:

'Done some....admin jobs. I didn't like it, me brothers just offered me a job there for $£ 260$ a week, but it would be just sitting down at the computer answering phones, I said I couldn't dey it. I need to do outdoors work or I couldn't work... I just couldn't handle that...'

Another young person compared working indoors to his experiences in prison. The distress of incarceration at a young age meant that it was impossible for him to envisage himself being confined to working indoors. Sixty percent of the young participants of this study suffered from mental health problems. Supervisors described working at the GL helping young people with these issues. Young people reported sleeping better, feeling calmer and being more focused since working outdoors. Naturally, improved mental wellbeing will allow one to feel that their life has greater value and therefore will engender meaning.

Being outdoors also appeared to be more conducive to learning for participants. Many young people expressed the difficulties they had experienced in trying to learn in a classroom setting and stated that they learned better when engaged in outdoor activities. This resonates with existing research, which indicates that there may be a cognitive advantage to spending time immersed in natural, rural areas or areas of urban 'greenspace' (Esteban, Harrison \& Murphy, 2012; Atchley, Strayer \& Atchley, 2012; Sproule et al., 2013). As identified earlier, many young people inherently valued opportunities to improve their knowledge/skills. Therefore, they also found meaning in working outdoors because it aided their desires to learn.

\section{Overall}

The findings indicate that youths with a history of offending have particular criteria for meaningful employment, which differs from that specified in existing scholarship (research mainly conducted with adult professionals). This is displayed in Table 1. 


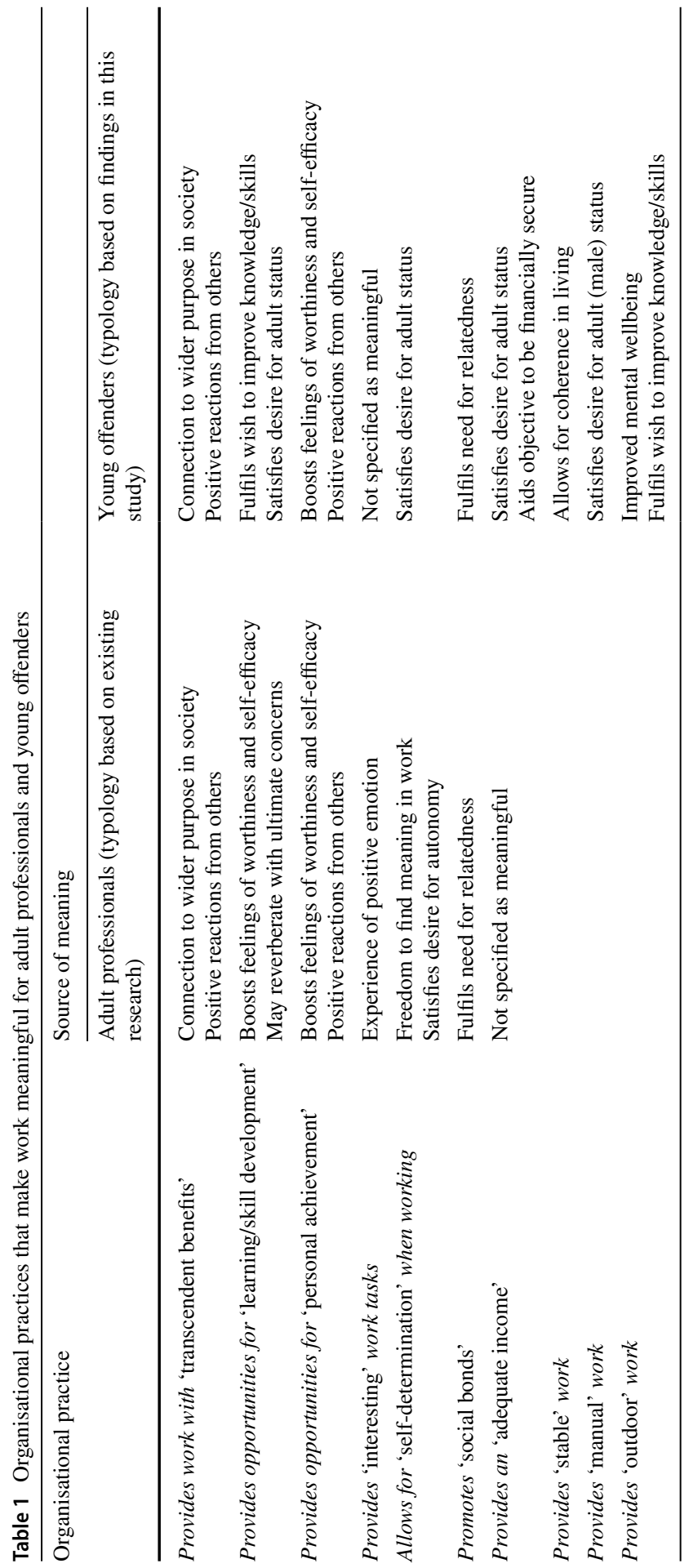




\section{Discussion}

The findings reveal that present understandings of meaningful employment-based upon research primarily conducted with well-educated, professional adults-do not fully resonate with more diverse groups, such as the participants in this study. Testing the applicability of the typology drawn from existing literature has revealed its limitations. There are organisational practices specified in existing meaningful employment scholarship that young offenders did not rate as particularly meaningful - such as the provision of 'interesting' work tasks. There are also organisational practices not specified in the existing literature that youths expressed as giving meaning to their work- such as the provision of outdoor and manual work tasks. Furthermore, even when participants described finding meaning in the same organisational practices as researchers have found with adult professionals, these could be for different reasons. Therefore, whilst several scholars provide- based on present understandings of meaningful work-strategies for employers to enhance work meaning for employees (see, for example, Dik et al., 2009, 2015; Lease et al., 2019; Lysova et al., 2019), it should be recognised that these may not be beneficial for all employees or in all work contexts.

The findings highlight the subjectivity of meaningful work. Young offenders' conceptions of meaningful employment were associated with their social position. As adolescents desiring autonomy, employment that felt the equivalent of that carried out by adults was meaningful to young people. This was work with opportunities for skill development, that allowed self-determined working and that provided an adequate income. Furthermore, young male offenders found meaning in physically demanding work because of the importance they attached to hegemonic working-class ideals of masculinity; such work provided a way to meet the masculine gender expectations of the communities in which these young people resided. Consequently, due to the subjectivity of meaningful work, scholars may find that if they include more diverse samples of employees in their research, they cannot form a single typology of meaningful work. It may vary depending on factors such as gender, age, ethnicity, and socioeconomic status.

Pratt and Ashforth (2003) purport that experiencing meaning helps us answer the question 'why am I here?', but naturally the first step to understanding 'why am I here?' is to first comprehend 'who am I?'. The individual's identity has a mediating role in determining what is meaningful. A number of scholars explain that if our employment role aligns with our self-concept, then experiences of meaning will follow; work can become a form of self-expression (Beadle, 2016; May et al., 2004; Pratt \& Ashforth, 2003). This was clearly illustrated in this study, where the young participants found meaning in work that allowed them to express a hegemonic masculine identity and their growing self-concept as an adult. ${ }^{6}$ As Dingfelder (2011:42) states, 'we create ourselves out of the stories we tell about our lives'. Thus, the selfnarrative can be understood as more than a retrospective record of life events; it aids

\footnotetext{
${ }^{6}$ For a more detailed discussion of young offenders' self-narratives and how they are influenced by external sources of meaning such as 'hegemonic masculine identity', see Oswald (2021).
} 
the formation of an individual's identity. Consequently, as this research highlights the relevance of identity to understandings of meaningful employment, it lends support therefore for techniques such as narrative career counselling (see Cochran, 1997).

The interaction between identity and meaning can also be a reciprocal one; finding meaning in our work can also influence our identity (Gini, 2000; Harding, 2019). Indeed, research demonstrates that the relationship between identity and meaning is particularly relevant during adolescence, as it is a period when individuals both engage more deeply in constructing their identity and seek to find meaning in life's activities (Negru-Subtirica et al., 2016; Steger \& Wong, 2012). For the participants in this study, their developmental stage is one where finding sources of meaning (for example, in employment) is of great importance for healthy identity formation. Finding a clear sense of purpose/meaning in life builds identity capital and aids adultidentity resolution (Côté, 2016). Thus, when attempting to comprehend the nature of 'meaningful work', we must be mindful of the developmental stage of the employee. For adolescents such as those in this study, it is a period in their development where their definitions of meaningful employment will reflect their need to more deeply construct their identities as young adults. The relevance of the participants' adolescence to their conceptualisation of meaningful work also suggests that experiences of meaningful work might change throughout an individual's life course.

In contrast to the findings with adults, young participants found job stability and income to be sources of meaning in themselves, not just preconditions for finding meaning elsewhere in employment. Again, this reflects their social circumstances; young people found inherent meaning in having a secure job because it gave a sense of coherence and purpose in their often-chaotic lives. Young people found meaning in earning a legitimate wage because of their regular exposure to the harms of poverty and because of their experiences of the stigma surrounding welfare dependency. Surveying a more diverse population of employees suggests therefore that scholars should not ignore the 'extrinsic' sources of meaning in employment. Whilst the more privileged in society might require more than a secure job that pays a 'living' wage to provide a sense of meaning in their lives, this might not be the case for those who lack access to material resources and consequently may experience low-quality/insecure housing, family dysfunction/domestic abuse, poor health and wellbeing, stress, social isolation and crime perpetration/victimisation (Dermott \& Main, 2018).

Nonetheless, despite this paper's assertion that young offenders discovered different sources of meaning in their work compared to the research with adult professionals, essentially these could be summarised as the same two sources for both groups. Indeed, in as much as the findings in this study demonstrate the limitations of existing meaningful employment scholarship, they also affirm its relevance. Steger et al.'s (2012) framework for understanding meaningful employment is particularly useful. They state that individuals can find 'psychological meaningfulness in work' to the extent that work aligns with and fulfils the individual's ideas of what is valuable in life. For adult professionals, these were to feel a sense of autonomy and experience relatedness. For young offenders, these were a desire for adult status, to experience relatedness and to achieve hegemonic ideals of masculinity. Work that fulfilled these 
values was meaningful. Furthermore, Steger, Dik and Duffy explain that individuals can find 'meaning making through work' where the work itself makes a broader contribution in discovering meaning. For both youths and adults, employment that connected them to a wider purpose, boosted feelings of worthiness and self-efficacy, and improved their mental wellbeing, allowed them to find meaning in their lives. Essentially such work gave them a stronger answer to 'why am I here?'. Also useful in interpreting these findings is Rosso et al.'s (2010) distinction between sources of meaningful work that arise from 'self-connection' (work actions that bring us into closer alignment with our self-view and values) and those that arise from 'individuation' (building self-esteem), 'contribution' (to something greater than the self) and 'unification' (bringing us into harmony with others). Thus, even with diverse samples, some generalisations may be able to be made regarding meaningful employment. Whilst finding 'self-connection' or 'psychological meaningfulness in work' will necessarily be subjective, and depend upon individual values, there may be certain organisational practices-such as those that build self-efficacy, connect us to others and contribute to a greater good-that universally generate 'meaning making through work'.

This study has sought to expand meaningful employment scholarship by exploring this with a population of young offenders. However, the typology presented in Table 1 may not apply to young offenders beyond the participants of this study for several reasons. Firstly, most interviews took place whilst young people were still partaking in the GL scheme. This may have informed their criteria for meaningful employment. For instance, it could not be determined whether the importance they attached to outdoor manual work was because this is what they were engaging in at the time. Secondly, all the participants in this study resided in Northern England, which has some of the lowest employment and highest economic inactivity rates in the UK (Office for National Statistics, 2021). Different work contexts where youth employment is more or less available may influence ideas of meaningful employment. Thirdly, the sample in this study contained only one female and three youths who were non-white. However, as the findings above would indicate, ideas of 'work' and 'meaning' can be influenced by cultural norms.

A final point of note is that the findings in this study demonstrate a considerable disparity between young people's conceptions of meaningful work and the employment it is likely this population will attain (outside the sphere of social enterprise that is-for a detailed discussion, see Soppitt et al., 2021). Winlow and Hall (2009) and Standing (2011) explain that due to deindustrialisation and neoliberalism, an increasingly significant portion of the workforce is employed in 'precariat occupations'. Such employment is unstable, low-paid, low-skilled, socially isolating and increasingly feminised service work. This stands in sharp contrast with young people's criteria for meaningful work specified in Table 1. Research confirms that precarious work often does not provide the necessary coherence, autonomy or relatedness to be experienced as meaningful (Allan, Rolniak \& Bouchard, 2020; Kim \& Allan, 2020; Patulny et al., 2020). Young offenders, because of the barrier of the criminal record and their (typical) lack of qualifications, are likely to reside in the precariat population. Indeed, those participants who progressed into further employment upon leaving the GL scheme were almost exclusively employed in insecure 
precariat work. Future research could explore how conceptions of meaningful employment are influenced by employment under such conditions.

\section{Conclusion}

Employees who have meaningful work experience greater mental wellbeing and are more productive and engaged; yet depersonalised, mundane and insecure work continues to grow. It is therefore vital that researchers strive for a more comprehensive understanding of 'meaningful employment' and how it is experienced by different populations. This article sought to explore conceptions of meaningful employment among young people with a history of criminal offending. Whilst the criteria for meaningful employment found in this study may not resonate with all young offenders, by investigating it with these participants, this study has revealed the limitations of current understandings of meaningful work. They may not resonate with groups beyond the adult professionals typically surveyed in this field. Indeed, exploring conceptions of meaningful employment among young offenders has highlighted how the individual's self-concept and inherent values can influence which organisational practices are meaningful. However, it has also demonstrated that there may be some instances where work itself makes a broader contribution in discovering meaning in life, regardless of the individual's prior values. It would be beneficial if future research could expand upon the findings of this article and search for commonalities in conceptions of meaningful employment among diverse samples, perhaps including other populations that are poorly represented in meaningful employment scholarship. This should allow for a more detailed comprehension of this concept. It is important to understand the subjectivities of the workforce, and how this might influence perceptions of meaningful employment, but also which organisational practices might be meaningful for all.

Funding This work was supported by the award of a Northumbria University PhD Scholarship.

Data Availability The datasets generated during the current study are not publicly available due to privacy/ethical restrictions but are available from the corresponding author on reasonable request.

\section{Declarations}

Ethics Approval This study was performed in line with the principles of the Declaration of Helsinki. Approval was granted by the Ethics Committee of Northumbria University on 21 March 2017.

Consent Informed consent was obtained from all individual participants included in the study.

Conflict of Interest The author declares no competing interest.

Open Access This article is licensed under a Creative Commons Attribution 4.0 International License, which permits use, sharing, adaptation, distribution and reproduction in any medium or format, as long as you give appropriate credit to the original author(s) and the source, provide a link to the Creative Commons licence, and indicate if changes were made. The images or other third party material in this article are included in the article's Creative Commons licence, unless indicated otherwise in a credit line to the material. If material is not included in the article's Creative Commons licence and your intended use is 
not permitted by statutory regulation or exceeds the permitted use, you will need to obtain permission directly from the copyright holder. To view a copy of this licence, visit http://creativecommons.org/licen ses/by/4.0/.

\section{References}

Allan, B., Autin, K. L., \& Duffy, R. D. (2016). Self-determination and meaningful work: Exploring socioeconomic constraints. Frontiers in Psychology, 7(71), 1-9.

Allan, B. A., Duffy, R. D., \& Collisson, B. (2018). Helping others increases meaningful work: Evidence from three experiments. Journal of Counselling Psychology, 65(2), 155-165.

Allan, B. A., Rolniak, J. R., \& Bouchard, L. (2020). Underemployment and well-being: Exploring the dark side of meaningful work. Journal of Career Development, 47(1), 111-125.

Ashforth, B. E., \& Kreiner, G. E. (1999). 'How can you do it?' Dirty work and the challenge of constructing a positive identity. Academy of Management Review, 24, 413-434.

Atchley, R., Strayer, D., \& Atchley, P. (2012). Creativity in the Wild: Improving Creative Reasoning through Immersion in Natural Settings. http://journals.plos.org/plosone/article?id=10.1371/journal. pone.0051474

Ayers, D. F., Miller-Dyce, C., \& Carlone, D. (2008). Security, dignity, caring relationships and meaningful work. Community College Review, 35(4), 257-275.

Bailey, C., \& Madden, A. (2015). Time reclaimed: temporality and the experience of meaningful work. Work, employment and society, 1-16.

Baumeister, R. F. (1991). Meanings of Life. Guilford Press.

Beadle, R. (2016). Virtue and the case for meaningful work. In A. G. Sison, G. R. Beabout, \& I. Ferrero (Eds.), Handbook of Virtue Ethics in Business and Management (pp. 1-9). Springer.

Bechky, B. A. (2003). Sharing meaning across occupational communities: The transformation of understanding on a production floor. Organisation Science, 14(3), 312-330.

Bowie, N. E. (1998). A Kantian theory of meaningful work. Journal of Business Ethics, 17, 1083-1092.

Braun, V., \& Clarke, V. (2006). Using thematic analysis in psychology. Qualitative Research in Psychology, 3(2), 77-101.

Bunderson, J. S., \& Thompson, J. A. (2009). The call of the wild: Zookeepers, callings, and the doubleedged sword of deeply meaningful work. Administrative Science Quarterly, 54, 32-57.

Caelli, K., Ray, L., \& Mill, J. (2003). Clear as mud: Toward greater clarity in generic qualitative research. International Journal of Qualitative Methods, 2(2), 1-13.

Carter, E. W., \& Lunsford, L. B. (2005). Meaningful work: Improving employment outcomes for transition-age youth with emotional and behavioural disorders. Preventing School Failure: Alternative Education for Children and Youth, 49(2), 63-69.

Caulfield, L., \& Hill, J. (2014). Criminological research for beginners: A student's guide. Routledge.

Christian, M. S., Garza, A. S., \& Slaughter, J. E. (2011). Work engagement: A quantitative review and test of its relations with task and contextual performance. Personnel Psychology, 64, 89-136.

Cochran, L. (1997). Career counselling: a narrative approach. Sage Publications.

Connell, R. (1995). Masculinities. Polity Press.

Côté, J. E. (2016). The Identity Capital Model: A handbook of theory, methods, and findings. Unpublished Manuscript, Department of Sociology, The University of Western Ontario, London, ON, Canada. Retrieved from https://ir.lib.uwo.ca/cgi/viewcontent.cgi?article=1038\&context=sociologyp $\mathrm{ub}$

Deci, E. L., Connell, J. P., \& Ryan, R. M. (1989). Self-determination in a work organization. Journal of Applied Psychology, 74, 580-590

Department for Education (2021b). Permanent and Fixed Period Exclusions in England. Academic Year 2018/19. https://explore-education-statistics.service.gov.uk/find-statistics/permanent-and-fixedperiod-exclusions-in-england

Department for Education (2021a). Children looked after in England including adoptions. Reporting year 2020. https://explore-education-statistics.service.gov.uk/find-statistics/children-looked-after-inengland-including-adoptions/2020

Dermott, E., \& Main, G. (2018). Poverty and Social Exclusion in the UK: Vol.1: Volume 1 - The nature and extent of the problem. Policy Press. 
Dik, B. J., Duffy, R. D., \& Eldridge, B. M. (2009). Calling and vocation in career counseling: Recommendations for promoting meaningful work. Professional Psychology: Research and Practice, 40, 625-632. https://doi.org/10.1037/a0015547

Dik, B. J., Duffy, R. D., Allan, B. A., O’Donnell, M. B., Shim, Y., \& Steger, M. F. (2015). Purpose and meaning in career development applications. The Counseling Psychologist, 43, 558-585. https://doi. org/10.1177/0011000014546872

Dingfelder, S. F. (2011). Our stories, ourselves. Monitor on Psychology, 42(1), 34-47.

Esteban, A., Harrison, L., \& Murphy, M. (2012). Natural Solutions: Nature's role in delivering wellbeing and key policy goals - opportunities for the third sector. http://dnwssx417g17s.cloudfront.net/ nefoundation/default/page/-/publications/Natural_solutions_webReady.pdf

Frankl, V. (1992). Man's search for meaning: An introduction to logotherapy. Beacon.

Fried, Y., \& Ferris, G. R. (1987). The validity of the job characteristics model: A review and meta-analysis. Personnel Psychology, 40, 287-322.

Gallagher, M. (2008). Power is not an evil: Rethinking power in participatory methods. Children's Geographies, 6(2), 137-150.

Ghaill, M. M., \& an. (1996). 'What about the boys?': Schooling, class and crisis masculinity. The Sociological Review, 44(3), 381-397.

Gibson, W., \& Brown, A. (2009). Working with Qualitative Data. SAGE.

Gini, A. R. (2000). My job, my self: Work and the creation of the modern individual. Routledge.

Grant, A. M. (2008). The significance of task significance: Job performance effects, relational mechanisms, and boundary conditions. Journal of Applied Psychology, 93, 108-124.

Grant, A. M., \& Hofmann, D. A. (2011a). It's not all about me: Motivating hospital handwashing by focusing on patients. Psychological Science, 22, 1494-1499.

Grant, A. M., \& Hofmann, D. A. (2011b). Outsourcing inspiration: The performance effects of ideological messages from leaders and beneficiaries. Organizational Behavior and Human Decision Processes, 116, 173-187.

Grant, A. M., Campbell, E. M., Chen, G., Cottone, K., Lapedis, D., \& Lee, K. (2007). Impact and the art of motivation maintenance: The effects of contact with beneficiaries on persistence behavior. Organizational Behavior and Human Decision Processes, 103, 53-67.

Grant, A. M., Dutton, J. E., \& Rosso, B. D. (2008). Giving commitment: Employee support programs and the prosocial sensemaking process. Academy of Management Journal, 51, 898-918.

Harding, N. (2019). Identity and meaningful/meaningless work. In R. Yeoman, C. Bailey, A. Madden, \& M. Thompson (Eds.), The Oxford Handbook of Meaningful Work (pp. 133-147). Oxford University Press.

Hicks, J. A., \& King, L. A. (2008). Religious commitment and positive mood as information about meaning in life. Journal of Research in Personality, 42, 43-57.

Hicks, J. A., Schlegel, R. J., \& King, L. A. (2010). Social threats, happiness, and the dynamics of meaning in life judgments. Personality and Social Psychology Bulletin, 36, 1305-1317.

Hirschi, A. (2012). Callings and work engagement: Moderated mediation model of work meaningfulness, occupational identity, and occupational self-efficacy. Journal of Counseling Psychology, 59(3), $479-485$.

Humphrey, S. E., Nahrgang, J. D., \& Morgeson, F. P. (2007). Integrating motivational, social, and contextual work design features: A meta-analytic summary and theoretical extension of the work design literature. Journal of Applied Psychology, 92, 1332-1356.

Johnson, M. (2002). Social origins, adolescent experiences, and work value trajectories during the transition to adulthood. Social Forces, 80(4), 1307-1341.

Kim, T., \& Allan, B. A. (2020). Underemployment and meaningful work: The role of psychological needs. Journal of Career Assessment, 28(1), 76-90.

King, L. A., Heintzelman, S. J., \& Ward, S. J. (2016). Beyond the search for meaning: A contemporary science of the experience of meaning in life. Current Directions in Psychological Science, 25(4), 211-216.

Lease, S. H., Ingram, C. L., \& Brown, E. L. (2019). Stress and health outcomes: Do meaningful work and physical activity help? Journal of Career Development, 46(3), 251-264.

Lips-Wiersma, M., \& Morris, L. (2009). Discriminating between 'meaningful work' and the 'management of meaning.' Journal of Business Ethics, 88, 491-511.

Lysova, E. I., Allan, B. A., Dik, B. J., Duffy, R. D., \& Steger, M. F. (2019). Fostering meaningful work in organizations: A multilevel review and integration. Journal of Vocational Behavior, 110(Part B), 374389. https://doi.org/10.1016/j.jvb.2018.07.004

MacDonald, R., \& Shildrick, T. (2007). Street corner society: Leisure careers, youth (sub)culture and social exclusion. Leisure Studies, 26(3), 339-355. 
Massoglia, M., \& Uggen, C. (2010). Settling down and aging out: Toward an interactionist theory of desistance and the transition to adulthood. American Journal of Sociology, 116, 543-582.

May, D. R., Gilson, R. L., \& Harter, L. M. (2004). The psychological conditions of meaningfulness, safety and availability and the engagement of the human spirit at work. Journal of Occupational and Organizational Psychology, 77, 11-37.

McDowell, L. (2003). Masculine identities and low-paid work: Young men in urban labour markets. International Journal of Urban and Regional Research, 27(4), 828-848.

Ministry of Justice (2021). Youth Justice Statistics 2019/20 England and Wales. https://assets.publishing. service.gov.uk/government/uploads/system/uploads/attachment_data/file/956621/youth-justice-stati stics-2019-2020.pdf

Moffit, T. E. (1993). Adolescence-limited and life-course-persistent antisocial behaviour: A developmental taxonomy. Psychological Review, 100(4), 672-701.

Negru-Subtirica, O., Pop, E. I., Luyckx, K., Dezutter, J., \& Steger, M. F. (2016). The meaningful identity: A longitudinal look at the interplay between identity and meaning in life in adolescence. Developmental Psychology, 52(11), 1926-1936.

Nikolova, M., \& Cnossen, F. (2020). What makes work meaningful and why economists should care about it. Labour economics, 65, 101847.

Nowell, L., Norris, J., White, D., \& Moules, N. (2017). Thematic analysis: Striving to meet the trustworthiness criteria. International Journal of Qualitative Methods, 16(1), 1-13.

Office for National Statistics (2021). Labour market in the regions of the UK. https://www.ons.gov.uk/emplo ymentandlabourmarket/peopleinwork/employmentandemployeetypes/bulletins/regionallabourmarket/ january 2021

Oswald. (2021). The impact of employment upon young offenders' identities. Howard Journal of Crime and Justice. In press

Park, Y., \& Choi, W. (2016). The effects of formal learning and informal learning on job performance: The mediating role of the value of learning at work. Asia Pacific Education Review, 17(2), 279-287.

Patulny, R., Mills, K. A., Olson, R. E., Bellocchi, A., \& McKenzie, J. (2020). The emotional trade-off between meaningful and precarious work in new economies. Journal of Sociology, 56(3), 333-355.

Pratt, M. G., \& Ashforth, B. E. (2003). Fostering meaningfulness in working and in work. In K. S. Cameron, J. E. Dutton, \& R. E. Quinn (Eds.), Positive organizational scholarship: Foundations of a new discipline (pp. 309-327). Barrett-Koehler.

Rosso, B. D., Dekas, K. H., \& Wrzesniewski, A. (2010). On the meaning of work: A theoretical integration and review. Research in Organisational Behaviour, 30, 91-127.

Routledge, C., Arndt, J., Wildschut, T., Sedikides, C., Hart, C. M., Juhl, J., et al. (2011). The past makes the present meaningful: Nostalgia as an existential resource. Journal of Personality and Social Psychology, $101,638-652$.

Ryan, R. M., \& Deci, E. L. (2000). Self-determination theory and the facilitation of intrinsic motivation, social development, and well-being. American Psychologist, 55(1), 68-78.

Ryan, R. M., \& Deci, E. L. (2017). Self-determination theory. Basic psychological needs in motivation, development, and wellness. Guildford Press.

Ryff, C. D., \& Singer, B. (1998). The role of purpose in life and personal growth in positive human health. In P. P. Wong \& P. S. Fry (Eds.), The human quest for meaning: A handbook of psychological research and clinical applications (pp. 213-235). Erlbaum Publishers.

Silvia, P.J. (2006). Exploring the Psychology of Interest. http://www.oxfordscholarship.com/view/0.1093/ acprof:oso/9780195158557.001.0001/acprof-9780195158557

Singer, P. (1995). How are we to Live? Prometheus Books.

Slutskaya, N., Simpson, R., Hughes, J., Simpson, A., \& Uygur, S. (2016). Masculinity and class in the context of dirty work. Gender, Work and Organization, 23(2), 165-182.

Soppitt, S., Oswald, R.J., \& Walker, S. (2021). Social enterprise and the sub-precariat. Social Enterprise Journal. In press.

Sproule, J., Martindale, R., Wang, J., Allison, P., Nash, C., \& Gray, S. (2013). Investigating the experience of outdoor and adventurous project work in an educational setting using a self-determination framework. European Physical Education Review, 19(3), 315-328.

Standing, G. (2011). The precariat: the new dangerous class. New York: Bloomsbury.

Steger, M. F., \& Wong, P. T. P. (2012). The human quest for meaning. Routledge.

Steger, M. F., Dik, B. J., \& Duffy, R. D. (2012). Measuring meaningful work: The work and meaning inventory. Journal of Career Assessment, 20(3), 322-337.

Swain, N. (2016). Oral language skills in young offenders [Unpublished presentation]. Newcastle University 
Taylor, C. (2016). Review of the Youth Justice System: an interim report of emerging findings. https://www. gov.uk/government/uploads/system/uploads/attachment_data/file/498736/youth-justice-review.pdf

Thomas, D. R. (2006). A general inductive approach for analyzing qualitative evaluation data. American Journal of Evaluation, 27(2), 237-246.

Veltman, A. (2015). Is meaningful work available to all people? Philosophy and Social Criticism, 41(7), $725-747$.

Ward, S. J., \& King, L. A. (2016). Poor but happy? Income, happiness, and experienced and expected meaning in life. Social Psychological \& Personality Science, 7, 463-470.

Winlow, S., \& Hall, S. (2009). Living for the weekend: Youth identities in Northeast England. Ethnography, 10(1), 91-113.

Wrzesniewski, A. (2003). Finding positive meaning in work. In K. S. Cameron, J. E. Dutton, \& R. E. Quinn (Eds.), Positive organizational scholarship (pp. 296-308). Berrett-Koehler. 